\title{
Structural and electrical properties of sintered zinc-titanate ceramics
}

\author{
Nina Obradovic ${ }^{\mathrm{a}, *}$, Nebojsa Mitrovic $^{\mathrm{b}}$, Vladimir Pavlovic ${ }^{\mathrm{a}}$ \\ ${ }^{a}$ Institute of Technical Sciences of SASA, Knez-Mihailova 35/IV, 11000 Belgrade, Serbia \\ b Joint Laboratories for Advanced Materials of SASA, Section for Amorphous Systems, Technical Faculty Cacak, 32000 Cacak, Serbia \\ Received 26 February 2007; received in revised form 20 July 2007; accepted 3 September 2007 \\ Available online 25 September 2007
}

\begin{abstract}
The aim of this work was an investigation of structural and electrical properties of sintered zinc-titanate ceramics obtained by mechanical activation. Mixtures of $\mathrm{ZnO}$ and $\mathrm{TiO}_{2}$ were mechanically activated in a planetary ball mill up to 90 min and sintered isothermally in air for 120 min at $1100{ }^{\circ} \mathrm{C}$. The phase composition in the $\mathrm{ZnO}-\mathrm{TiO}_{2}$ system after milling and sintering was analyzed using the XRD method. Microstructure analyses were performed using SEM. The results of electric resistivity, capacitance and loss tangent of the sintered samples were obtained. The existence of zinc-titanate as a dielectric was proved $\left(\varepsilon_{\mathrm{r}}=12.5, Q=386.1, \operatorname{tg} \delta=0.0026, \rho=1.02 \Omega \mathrm{m}\right)$.
\end{abstract}

(C) 2007 Elsevier Ltd and Techna Group S.r.l. All rights reserved.

Keywords: A. Milling; A. Sintering; B. X-ray methods; C. Electrical properties

\section{Introduction}

Oxides with a spinel structure are some of the most studied compounds in solid-state sciences due to their wide range of applications. Commonly, they are used as humidity sensors, semiconductors, magnetic materials, catalysts, microwave dielectrics and others [1,2].

A variety of titanates, such as $\mathrm{ZnTiO}_{3}, \mathrm{Zn}_{2} \mathrm{Ti}_{3} \mathrm{O}_{8}$ and $\mathrm{Zn}_{2} \mathrm{TiO}_{4}$, can be simultaneously obtained by a classic solid-state route $[3,4]$. It is well known that mechanical activation is a widely used method, which enhances the mixture homogeneity of the starting components; their reactivity and can remarkably lower the reaction temperature. Unfortunately, only a few researchers applied this method for obtaining zinc-titanate $[2,5] . \mathrm{Zn}_{2} \mathrm{TiO}_{4}$ prepared by the conventional solid-state reaction between $2 \mathrm{ZnO}$ and $1 \mathrm{TiO}_{2}$ was also reported in our previous study [6].

In this study, the authors have attempted to reveal the influence of milling conditions on structural and electrical properties of sintered zinc-titanate ceramics.

\section{Experimental procedure}

Mixtures of $\mathrm{ZnO}\left(99.9 \%\right.$ Kemika-Zagreb) and $\mathrm{TiO}_{2}$ powders (99.9\% Alfa product-Ventron) with a molar ratio of $\mathrm{ZnO}$ :-

\footnotetext{
* Corresponding author. Tel.: +381 112027 203; fax: +381 11185263 .

E-mail address: ninao@bib.sanu.ac.yu (N. Obradovic).
}

$\mathrm{TiO}_{2}=2: 1$ were mechanically activated by grinding in a planetary ball mill (Fritsch Pulverisette 5). The milling process was performed in air during 5, 30 and $90 \mathrm{~min}$ at the basic disc rotation speed of $320 \mathrm{rpm}$ and a rotation speed of bowls of $400 \mathrm{rpm}$.

Zirconium oxide balls (approx. $10 \mathrm{~mm}$ in diameter) and bowls $\left(500 \mathrm{~cm}^{3}\right)$ were used with a ball to powder mixture mass ratio of 40:1. Samples were denoted as ZTO-005 to ZTO-090 according to the milling time. The binder-free powders were compacted using the uniaxial double action pressing process in an $8 \mathrm{~mm}$ diameter tool (Hydraulic press RING, P-14, VEB THURINGER). Compacts were placed in an alumna boat and heated in a tube furnace (Lenton Thermal Design Typ 1600). The heating rate was $10{ }^{\circ} \mathrm{C} / \mathrm{min}$ and when the temperature of the furnace reached $1100{ }^{\circ} \mathrm{C}$, compacts were sintered isothermally in air atmosphere for $120 \mathrm{~min}$. The density of specimens was calculated from precise measurements of specimen's diameter, thickness and mass.

X-ray powder diffraction patterns of the milled powder mixtures and sintered samples were obtained using a NorelicoPhilips PW-1050 diffractometer, with a $\mathrm{Cu} \mathrm{K} \alpha$ radiation and a step scan mode of $0.02^{\circ} / 0.4 \mathrm{~s}$.

The morphology of obtained powders was characterized using scanning electron microscopy (JSM 5300-JEOL, $30 \mathrm{kV}$ ).

The measurements of electrical resistivity, capacitance and loss tangent of samples were measured in the frequency range from $400 \mathrm{~Hz}$ to $4 \mathrm{MHz}$ frequencies with a HIOKI 3532-50 LCR 
HiTESTER device at a constant voltage mode (amplitude $0.5 \mathrm{~V}$ of sinusoidal signal applied to the specimens). The "fourprobe" configuration has been employed. The samples were prepared by painting silver electrodes on both sides following with thermal treatment at $120{ }^{\circ} \mathrm{C}$ for $2 \mathrm{~h}$ performed in order to improve the paint conductivity.

\section{Results and discussion}

According to our X-ray analysis [7], intensive milling of $\mathrm{ZnO}-\mathrm{TiO}_{2}$ powder mixture leads to the decrease of crystallinity, occurring as a consequence of defect formation and diminution of crystallite size, and the formation of a zinctitanate phase, occurring as a consequence of a solid-state reaction between $\mathrm{ZnO}$ and $\mathrm{TiO}_{2}$.

We have noticed that: intensities of all starting phases are significantly lowered after $5 \mathrm{~min}$ of mechanical treatment, the first significant appearance of a zinc-titanate phase along with

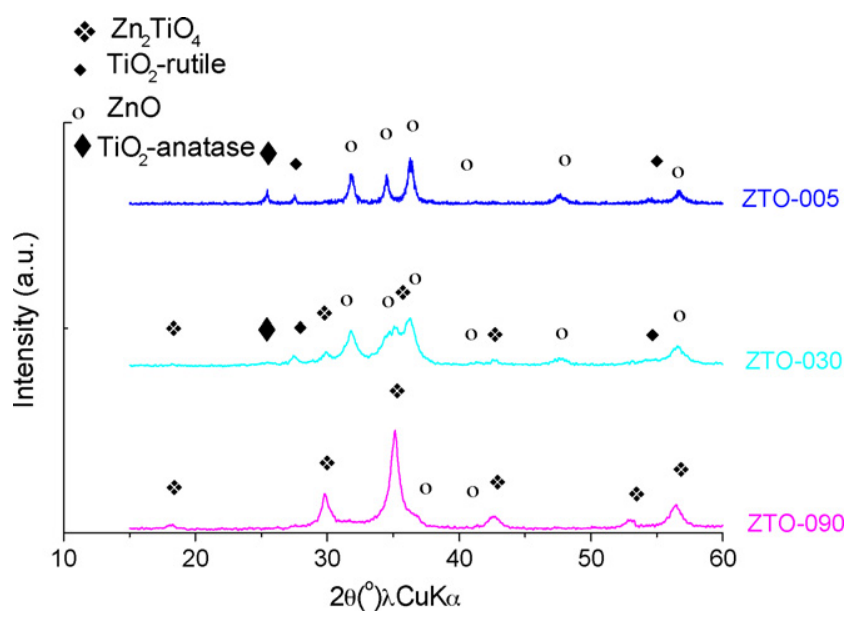

Fig. 1. XRD patterns of samples activated 5, 30 and $90 \mathrm{~min}$.

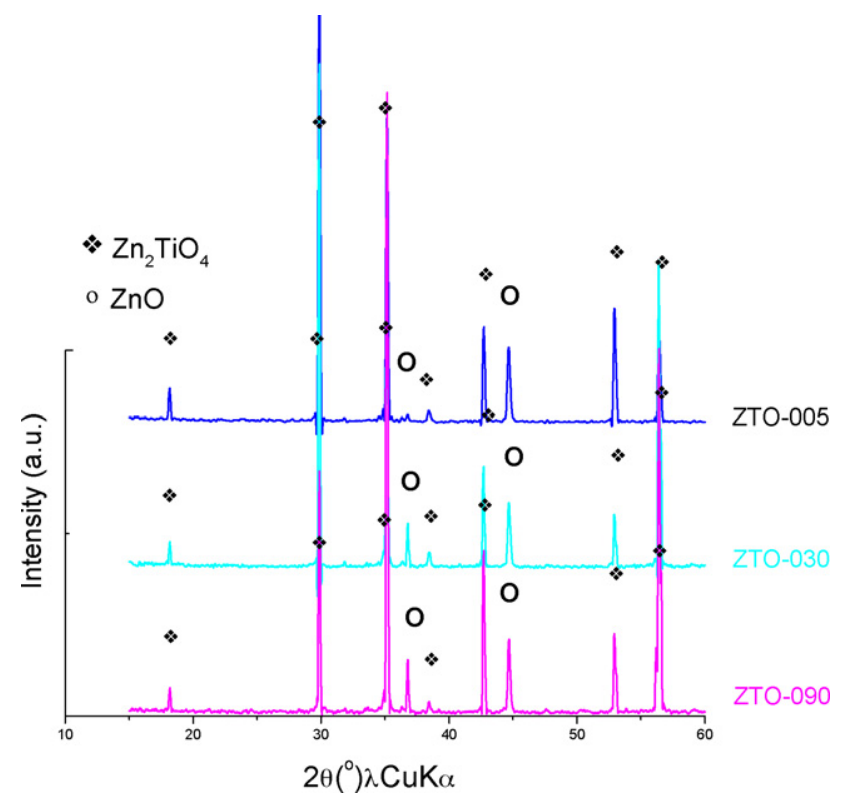

Fig. 2. XRD patterns of samples activated 5, 30 and $90 \mathrm{~min}$ and sintered at $1100{ }^{\circ} \mathrm{C}$ for $2 \mathrm{~h}$. all the starting phases is established to be after $30 \mathrm{~min}$ of mechanical treatment and the formation of an $\alpha$-spinel $\mathrm{Zn}_{2} \mathrm{TiO}_{4}$ (cubic, space group $F d 3 m$ ) phase occurs after 90 min of milling (Fig. 1). After sintering, only a pure zinc-titanate phase with a

(a)

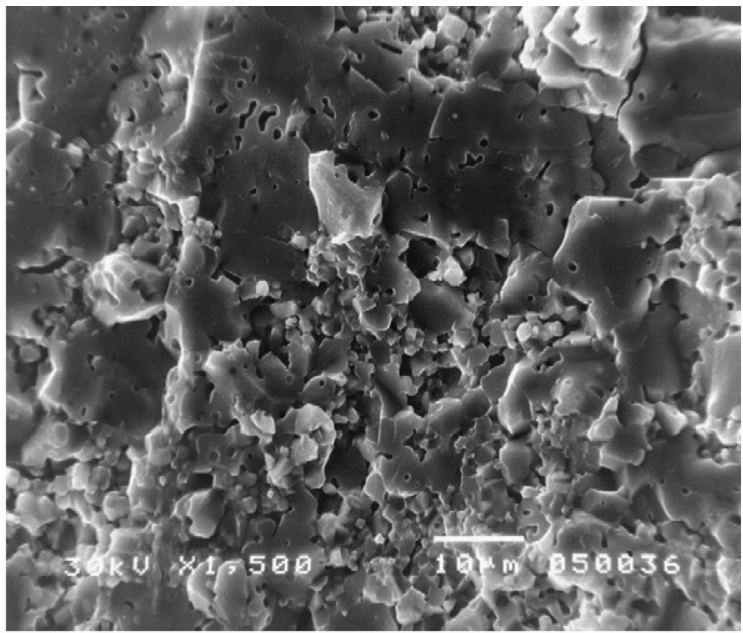

(b)

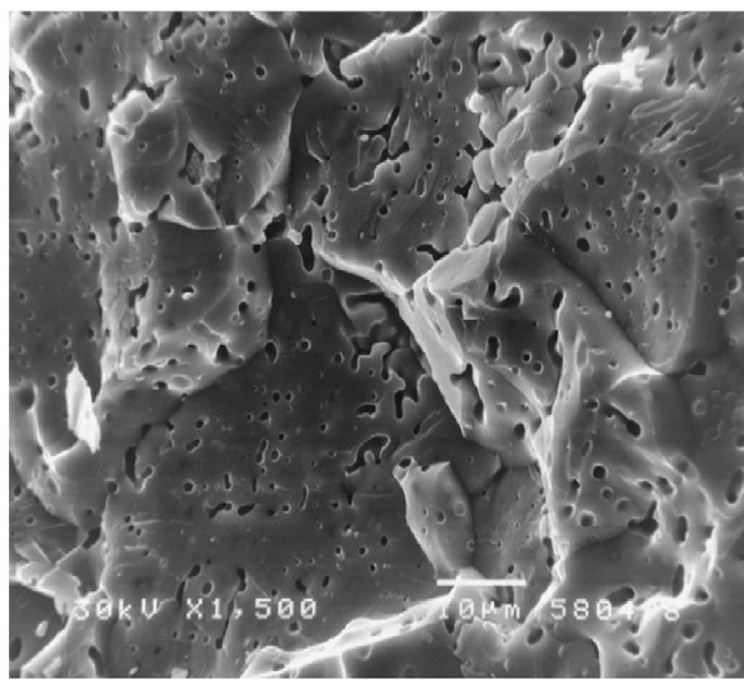

(c)

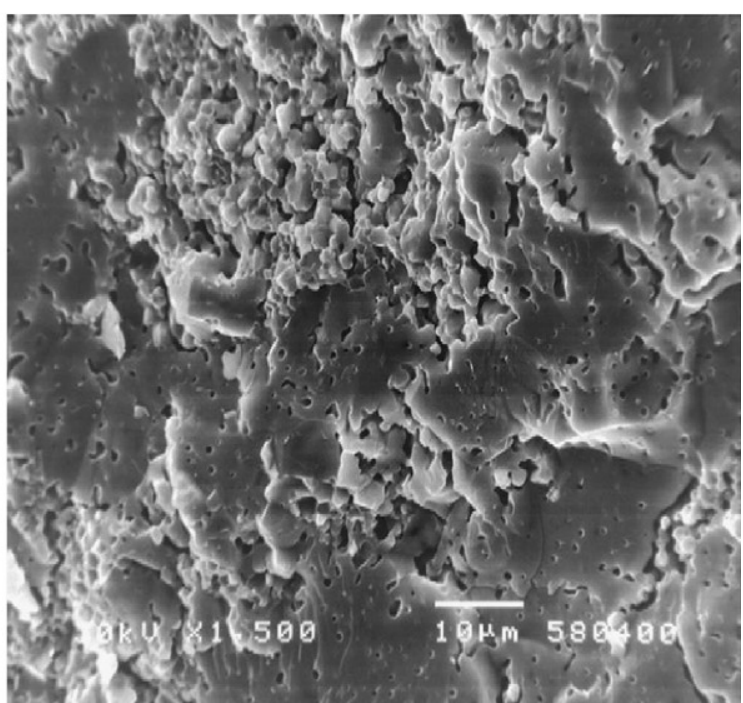

Fig. 3. SEM micrographs of samples activated (a) 5, (b) 30 and (c) 90 min and sintered at $1100{ }^{\circ} \mathrm{C}$ for $2 \mathrm{~h}$. 
Table 1

Electrical properties (at the $4 \mathrm{MHz}$ frequency) and relative densities of samples activated 5, 30 and $90 \mathrm{~min}$ and sintered at $1100{ }^{\circ} \mathrm{C}$ for $2 \mathrm{~h}$

\begin{tabular}{llllll}
\hline Sample & $d_{\mathrm{S}}(\% \mathrm{TD})$ & $\varepsilon_{\mathrm{r}}$ & $Q$ & $\operatorname{tg} \delta\left(\times 10^{-3}\right)$ & $\rho(\Omega \mathrm{m})$ \\
\hline ZTO-005 & 90.93 & 10.06 & 117.4 & 8.52 & 4.02 \\
ZTO-030 & 92.20 & 12.15 & 386.1 & 2.59 & 1.02 \\
ZTO-090 & 90.40 & 11.92 & 265.2 & 3.77 & 1.45 \\
\hline
\end{tabular}

small amount of unreacted $\mathrm{ZnO}[8]$ is observed (Fig. 2). It is obvious that the reflections of the sintered samples are sharper and more intensive compared to the activated ones, due to recrystallization, the disappearance of defects and grain growth that occur during sintering.

The evolution of microstructure constituents, grains and pores occur during the sintering process, where with the increase of temperature and prolonged time of sintering, the adequate processes of grain growth and decrease of pore size are taking place. Microstructure analysis (Fig. 3) showed that mechanical activation not only increased sintering densities of the samples, but also led to the increase of contact necks and strengthening of boundary regions of neighboring grains. As a result, microstructure of fractured surfaces of the samples showed that the fracture occurred both between grain boundaries and through the grains. According to our analysis the most homogenous microstructure was obtained for the sample activated $30 \mathrm{~min}$.

The results of microstructure development are in accordance with dielectric properties of the samples. The values of densities obtained after sintering $\left(d_{\mathrm{S}}\right.$, given in percents of theoretical density of $\mathrm{Zn}_{2} \mathrm{TiO}_{4}$ ), quality factor $(Q)$, dielectric permittivity $\left(\varepsilon_{\mathrm{r}}\right)$ and specific resistance $(\rho$, given in $\Omega \mathrm{m})$ are given in Table 1.

The electrical measurements pointed out that dielectric permittivity of the specimens increased with activation time and then decrease slightly after reaching its maximum for the sample activated $30 \mathrm{~min}$. It is believed that the densities play an important role in controlling dielectric loss, as has been often found in other microwave dielectric materials [9]. The $Q$ value is generally affected not only by the lattice vibrational modes, but also by the pores, the second phases, the impurities, the lattice defect, crystallizability and inner stress [10]. According to our analysis, since a higher density resulted in a higher dielectric permittivity owing to the lower porosity for the fixed sintering temperature and since the amount of the secondary phase is very small, as observed from XRD patterns, the effect of the poly-phase mixture on dielectric permittivity change is less sensitive than the density effect. The increase in activation time is beneficial to the densification after sintering and crystallizability until the $Q$ value reaches the maximum. The further increase in activation time will result in the appearance of abnormal grains and pores after sintering process and consequently lead to the reduction of the $Q$ value.

This suggests that, for the activation and sintering conditions we used, a higher density and the homogeneity of morphology [11] are dominantly responsible for the higher values of dielectric permittivity of the samples.

\section{Conclusions}

In this article the influence of mechanical activation of the $\mathrm{ZnO}-\mathrm{TiO}_{2}$ system on structural and electrical properties of sintered zinc-titanate ceramics has been examined. It was noticed that the first significant appearance of zinc-titanate phase along with all the starting phases is established to be after $30 \mathrm{~min}$ of mechanical treatment, although the very first diffraction peaks are detectable after $15 \mathrm{~min}$ of activation. A pure zinc-titanate phase with a small amount of unreacted $\mathrm{ZnO}$ in all samples has been synthesized successfully after the sintering process. Microstructure analyses showed that mechanical activation led to the increase of contact necks and strengthening of boundary regions of neighboring grains thus influencing the final density and electrical properties of the samples.

\section{References}

[1] Z.V. Marinkovic, L. Mancic, O. Milosevic, The nature of structural changes in nanocrystalline $\mathrm{ZnO}$ powders under linear heating conditions, J. Eur. Ceram. Soc. 25 (2005) 2081-2084.

[2] S.K. Manik, P. Bose, S.K. Pradhan, Microstructure characterization and phase transformation kinetics of ball-milled prepared nanocrystalline $\mathrm{Zn}_{2} \mathrm{TiO}_{4}$ by Rietveld method, Mater. Chem. Phys. 82 (2003) 837-847.

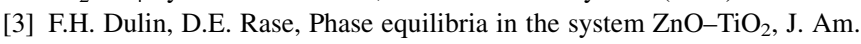
Ceram. Soc. 43 (1960) 125.

[4] U. Steinike, B. Wallis, Formation and structure of Ti-Zn-oxides, Cryst. Res. Technol. 32 (1997) 187.

[5] H.T. Kim, J.D. Byun, Y. Kim, Microstructure and microwave dielectric properties of modified zinc titanates, Mater. Res. Bull. 33 (1998) 975-986.

[6] N. Obradovic, N. Labus, T. Sreckovic, D. Minic, M.M. Ristic, Synthesis and characterization of zinc titanate nano-crystal powders obtained by mechanical activation, Sci. Sint. 37 (2005) 123-129.

[7] N. Obradovic, N. Labus, T. Sreckovic, M.M. Ristic, The influence of trybophysical activation on $\mathrm{Zn}_{2} \mathrm{TiO}_{4}$ synthesis, Mater. Sci. Forum 518 (2006) 131-136.

[8] B. Li, Z. Yue, L. Li, J. Zhou, Z. Gui, Low-fired microwave dielectrics in $\mathrm{ZnO}-\mathrm{TiO}_{2}$ ceramics doped with $\mathrm{CuO}$ and $\mathrm{B}_{2} \mathrm{O}_{3}$, J. Mater. Sci.-Mater. Electron. 13 (2002) 415-418.

[9] J. Zhu, E.R. Kipkoech, W. Lu, Low firable $\mathrm{BiNbO}_{4}$ based microwave dielectric ceramics, J. Eur. Ceram. Soc. 26 (2006) 2027.

[10] W. Lei, Microwave dielectric properties of $\mathrm{ZnAl}_{2} \mathrm{O}_{4}-\mathrm{TiO}_{2}$ spinel-based composites, Mater. Lett. 61 (2007) 4066-4069.

[11] X. Liu, et al., Synthesis, low-temperature sintering and the dielectric properties of the $\mathrm{ZnO}-(1-x) \mathrm{TiO}_{2}-x \mathrm{SnO}_{2}(x=0.04-0.2)$, Mater. Res. Bull. 43 (2008) 693-699. 